\title{
ОТ ПРОСТОРОВ К ПРОСТРАНСТВАМ: \\ О ПОИСКЕ ГЕОГРАФИИ В КНИГЕ О ГЕОГРАФИИ
}

Рецензия на коллективную монографию

под ред. С.А. Панарина «От века бронзового до века

цифрового: феномен миграции во времени»

ФЁдОР ПОПОВ

\begin{abstract}
Размышления о невозможности комплексного изучения мигращий без обращения к географии как способу познания действительности. На примере коллективной монографии, созданной без непосредственного участия географов, показывается, что пространственная природа феномена проявляется даже при формальном отсутствии внимания к ней. Коллективный труд по исследованию миграций сравнивается с воображённым атласом: за каждым из разделов монографии стоит своя воображённая карта или серия карт, которые связаны между собой как общей структурой книги, так и множеством внутренних отсылок и перекличек.
\end{abstract}

Ключевые слова: коллективная монография, миграции, история миграџий, перемещение, пространство, география, воображённая карта, атлас.

Неписаные правила научного этикета требуют, чтобы составитель коллективной монографии в обязательном порядке извинился перед читателем во вступлении к книге за то, что та, по его мнению, вышла недостаточно цельной, структурированной, сюжетно выдержанной. Такова будто бы неизбежная плата за возможность аккумулировать под одной обложкой знания и опыт специалистов разного профиля, разных взглядов, разного культурного бэкграунда. За предисловием к каждой такой работе стоит незримый и недостижимый образ идеального коллективного труда - пестрого, но монолитного, многоголосого, но логически выверенного, внутренне разнородного, но полностью подчиненного единой идее, глобального как по замыслу, так и по исполнению.

Составитель и научный редактор представляемой монографии Сергей Панарин не отходит от сложившейся традиции, уравновешивая громкое заглавие скромным указанием в предисловии на «самый первый, можно сказать, стихийный, приступ к совместной работе...» [30] и сопровождая подчеркиваемое им же разнообразие авторских позиций и поднимаемых частных вопросов непритязательным сравнением со случайной выборкой. В этом отношении визуально органично смотрится и проскользнувшая в заключении отсылка (в другом контексте и с другими целями) к гипотетизму Марка Эпштейна, в котором «дерзость посылок сопрягается с кротостью выводов» [320]. Получившаяся, пусть, возможно, и непреднамеренно, перекличка между двумя «рамочными» разделами книги удачно оттеняет ее почти ритуальный дуализм.

ФЁДОР АРКАДЬЕВИч ПоПОВ (fpopov15@gmail.com), МОСКОВСКИЙ ГОСУДАРСТВЕННЫЙ УНИВЕРСИТЕТ им. М.В. ЛОМОНОСОвА, РосСИЯ.

СТАТЬЯ ПОСТУПИЛА В РЕДАКЦИЮ В МАЕ 2018 Г. 
Замах у монографии действительно масштабный. Только из заглавия и тринадцати строчек аннотации можно сделать вывод о как минимум трех аспектах, в которых она претендует на глобальность. Во-первых, это то, на чем делается основной акцент в позиционировании книги, - широкие временные рамки, охватывающие более трех тысячелетий от кризиса бронзового века до сегодняшних дней. При этом корпус текстов не расслаивается на «исторический» и «современный» блоки, поскольку многие авторы сами разворачивают свои частные исследования вдоль ленты времени, рассматривая современность лишь как актуальный срез изучаемых миграционных процессов.

Во-вторых, это планетарный охват: отсутствие заявленных пространственных рамок всего проекта позволяет считать, что его создатели стремились ухватить феномен не только во всем историческом, но и во всем географическом разнообразии, хотя среди разделов и ощущается объяснимый перекос в сторону «восточных» сюжетов, а, например, обе Америки начисто выпадают из поля зрения авторов.

В-третьих, - и это традиционный «козырь» в руках составителей коллективной монографии - ее крайне разношерстный авторский коллектив. Тематика миграций не монополизирована ни одним научным направлением, что делает их перспективным объектом междисциплинарных исследований. Среди авторов книги (на что обращается внимание и в предисловии, и в аннотации) присутствуют историки, международники, этнологи, археологи, социологи, антропологи, политологи, социальные психологи, филологи. Список выглядит исчерпывающим - за одним исключением.

Среди авторов нет ни одного географа.

Разумеется, это никак нельзя счесть упреком составителям монографии, винить в этом географы могут только себя (внимание к междисциплинарным проектам никогда не было сильной стороной российского географического сообщества). И в то же время миграция как процесс пространственно детерминированный, сводимый в пределе к перемещению человека из точки А в точку Б, буквально требует географического взгляда, тем более если коллективный труд притязает, пусть и неявно, на комплексность подходов к исследованию миграций. Можно ли изучать пресловутые «стрелочки на карте», не имея ни карт, ни даже самих стрелочек? Без географов в коллективе и без географии в арсенале?

Ответ получается дифференцированным. Без географов - увы, можно. Без географии - боюсь, нельзя. Без географии, по-видимому, просто не получится. И данная коллективная монография - с почти мак-наббсовским равнодушием к географии как к научной дисциплине, единственной (!) картой на 436 страницах и горсткой ссылок на Ж.А. Зайончковскую - есть в гораздо большей степени книга о географии, чем иные «сертифицированные» географические труды. И дело даже не в наличии отдельной главы, посвященной влиянию природных факторов на миграции: вопреки распространенному мнению, география - это не только природа, географические факторы не тождественны природным. География изучает пространство, а пространство здесь сквозит в каждом сюжете, проступает в каждом разделе, причем порой настолько явно, что невольно хочется процитировать (слегка не к месту) мультипликационного пирата Черного Пса, вопрошавшего «Где карта, Билли? Нам нужна карта...». Карт действительно остро не хватает - а это значит, что есть что картировать. 
Особенно любопытно выглядит вступительная статья Сергея Панарина, задуманная как своего рода поклон Старику Времени, но в то же время насквозь пропитанная географическими по сути и духу измышлениями. Рассуждая о семантическом дрейфе понятия «миграция», автор постоянно держит в поле зрения его смысловое ядро, на которое наслаиваются (и от которого отслаиваются) текущие оттенки восприятия, - миграция есть движение в пространстве, перемещение, переселение, вектор, та самая «стрелочка» на (мысленной) карте. И вся эволюция человечества, более того, сам процесс антропогенеза, предстает в виде непрекращающегося движения вдоль таких стрелочек. Общественная история во всей своей полноте элементарно кладется на карту, причем не потому, что это возможно, а потому что это необходимо. Совсем не кроткие заключения даже для географа. Отдельных слов заслуживает язык, на котором все это излагается. Миграция как «путь от свободных просторов - к пространствам, человеком-мигрантом одновременно расширяемым, разграничиваемым и изменяемым» [17] - такой цитатой, без сомнения, гордился бы любой убежденный географ (да простит меня автор за то, что я беззастенчиво сократил ее и в таком виде вынес в заглавие рецензии).

Прочие разделы монографии, составляющие еe содержательное «тело», в большинстве своем скорее игнорируют пространственность раскрываемых в них сюжетов, чем подчеркивают ее. Из общего ряда выпадают два текста. Прежде всего, это анализ трансформации системы социокультурных границ внутри казахстанского общества под действием миграций, проведенный Александром Алексеенко и Ольгой Колесниковой. Хотя формально социокультурные границы не всегда четко выражены в пространстве, рассмотрение их в связи с миграционными процессами автоматически переводит их в территориальную плоскость, превращает в географические объекты, что позволяет авторам делать такие - вполне географические по сути - выводы, как «Фактически шло переселение из одного «параллельного мира» в другой, и пересечение границы «миров» имело для казахов гораздо более глубокие последствия, чем пересечение государственной границы эмигрирующими русскими» [190]. Понятие границы используется и в других разделах, но, увы, без соответствующей рефлексии.

Другой нетипичный для данной монографии текст - это эссе Мариям Арпентьевой, посвященное феномену цифрового номадизма. Помещая в фокус исследования «нового кочевника», мобильного профессионала (журналиста, бизнесмена, студента), существующего в рамках нового же внепространственного и вневременного бытия, автор нарочито дегеографизирует текст, практически полностью очищая его от топонимов и любых других территориальных привязок. Такое выпячиваемое отвержение пространственности рассматриваемых процессов, как бы это странно ни звучало, является прямым доказательством признания автором географической природы миграций: провозглашение выхода на пределы некоторой системы координат означает как минимум подтверждение существования данной системы координат.

Что касается остальных разделов, то они, повторимся, склонны молчаливо обходить вниманием пространственные аспекты миграционных процессов. Для части из них это более или менее оправдано: в основном, это тексты из второй половины книги, посвященные восприятию мигрантов в странах-акцепторах, воздействию привнесенного мигрантами культурного и языкового багажа на структуру принимающего общества и др., 
т.е. те, в которых изучаются именно последствия миграций, а не сами миграции, где исходные перемещения де-факто выносятся за пределы области исследования. Впрочем, как минимум, поясняющая карта не помешала бы ни одному из разделов книги.

Как бы то ни было, основная масса текстов сфокусирована непосредственно на миграциях и тем самым крепко завязана на пространстве: помимо поисков ответов на вопросы «кто», «когда», «почему», «зачем» и «к чему это приведет», в соответствии с которыми строится рубрикация книги, большинство авторов так или иначе сталкиваются с вопросами «откуда», «куда» и «каким путем». Одни сосредоточиваются на определении областей исхода мигрантов, другие подробно разбирают их размещение в регионах прибытия, третьих более всего интересует сам путь, направление движения, четвертые заняты анализом всего поля, на котором протекают миграционные процессы. Для одних погружение в пространство сводится к дифференциации стран, откуда приезжают или куда устремляются мигранты, другие работают с целостными регионами, насыщая текст бессчетным числом топонимов, маркирующих перемещения, третьи опускаются на внутригородской уровень, рассуждая в категориях этнических кварталов, исторических центров и примыкающих улиц. Отвернуться от пространства оказывается не так просто оно само вторгается в рассуждения и где-то даже устанавливает свои порядки. О непрошенности гостя напоминает лишь отсутствие карт, без которых текст местами сползает в трудно перевариваемое нагромождение географических названий.

Иными словами, добрая половина включенных в книгу текстов оказываются похожими (где-то частично, а где-то и целиком) на аналитические записки при несуществующих картах. Некоторые разделы и вовсе оборачиваются их скрупулезным описанием, фактическим воплощением карт в тексте. И если уйти дальше в область сравнений и представить, что за каждым или почти каждым разделом стоит воображенная географическая карта, то вся коллективная монография предстает воображенным географическим атласом. Аналогия немного неуклюжая, но, если вдуматься, не столь уж и наивная.

Атлас - это не просто механическое собрание сюжетно близких карт, а их система, и ровно то же самое, только в отношении научных текстов, можно сказать и о коллективной монографии. Разница здесь в том, что атлас - даже если он и создан группой авторов гораздо проще подчинить единой идее, единому заданию, заранее унифицирующему нужным образом все кирпичики-карты, тогда как коллективную монографию даже при ясности замысла приходится собирать из неизменно разнородных элементов. Но если в представленной в предисловии характеристике идеальной коллективной монографии, «в которой под пестроцветьем сюжетов и исследовательских техник уже кристаллизовалась некая внутренняя, объективная, логика, связывающая все собрание текстов воедино, так что мне, как редактору, остается лишь ее проявить и, следуя ей, структурировать весь корпус текстов, убедительно разбив его на части, главы и разделы глав» [30], заменить все «тексты» на «карты», не превратится ли она в характеристику идеального коллективного атласа?

Атлас предполагает определенную взаимообусловленность составляющих его карт, дополняющих и обогащающих друг друга. В представленной монографии разделы также не существуют автономно, даром что писались разными авторами. Между текстами полно 
перекличек - не столь заметных, чтобы бросаться в глаза, но при этом способствующих сближению составных частей единого произведения. Хунну и жуань-жуани кочуют из раздела в раздел, Зигмунт Бауман разъясняет свою теорию сразу в нескольких местах книги, то там, то здесь мелькают оралманы, вырастают чайнатауны, под разным соусом обсуждается двойственность этнических кварталов. Цифровые номады, промчавшиеся сквозь вторую главу, неожиданно возвращаются в последнем разделе - уже под именем трансмигрантов. Некоторые сюжеты (феномен монголтауна в Сеуле, трансформация этнической идентичности у гагаузов) удостаиваются специального превью в более ранних разделах. Наконец, отдельные главы строятся по принципу сталкивания и противопоставления разных точек зрения на один и тот же вопрос - к примеру, на миграционный кризис в Европе начала XXI века или на изменение отношения россиян к приезжим из ближнего зарубежья. И так далее.

Комплексность, масштабность при сохранении детальности, цельность при сохранении внутреннего разнообразия - эти качества в равной степени присущи качественному атласу и качественной коллективной монографии. Все данные условия в той или иной степени соблюдены и здесь. Лежащая перед нами книга - это действительно целый атлас, в котором воображенные карты разных лет наслаиваются друг на друга, отражаются друг в друге, соотносятся в разных формах, образуя, в конечном счете, лоскутную репрезентацию целостного четырехмерного пространства движения, пространства истории, сформированного человеком-мигрантом посредством упомянутого постоянного расширения, разграничения и изменения.

При этом каждый из разделов сам по себе представляет минимальный интерес, не будучи предназначен для восприятия в отрыве от остального контента. Интересна именно общая картина, итоговая мозаика, атлас во всей своей полноте. Полагаю, что это - лучший комплимент составителю коллективной монографии. И все же...

Где карта, Билли? Нам нужна карта.

\section{ЛИТЕРАТУРА}

От века бронзового до века цифрового: феномен миграции во времени (2018).

Коллективная монография / Сост., науч., лит. ред. С.А. Панарин; ред. англ. текстов А.А. Космарский. Барнаул: Издательство Алтайского университета. 436 с. ISBN 978-57904-2258-4. 


\title{
FROM EXPANSE TO SPACE: THE SEARCH FOR GEOGRAPHY IN A BOOK ON GEOGRAPHY \\ Review of a collective monograph «Migration throughout times: From the bronze age to the century of the digital».
}

\section{Ed. by S. Panarin}

\section{FEDOR POPOV}

\begin{abstract}
An essay on the impossibility of studying migration without recourse to geography as a way to understand reality. Using as an example a collective monograph made without the direct involvement of geographers, it is shown that the spatiality of the phenomenon of migration manifests itself even when it is paid no special attention. The collective work on migration here reviewed is compared to an imagined atlas: behind each section is an imaginary map or series of maps, all of which are interconnected by the book's overall structure as well as by the numerous internal references and overlaps.
\end{abstract}

Key words: collective monograph, migration, history of migrations, moving, space, geography, imagined map, atlas.

Fedor Popov (fpopov15@gmail.com), Lomonosov Moscow State University, Russia.

DATE RECEIVED : MAY 2018.

\section{REFERENCES}

Ot veka bronzovogo do veka tsifrovogo: fenomen migratsii vo vremeni [Migration throughout times: from the bronze age to the digital age] (2018). Kollektivnaya monografiya [A collective monograph] / Compiled and edited by S.A. Panarin; editor of texts in English A.A. Kosmarsky. Barnaul: Izdatel'stvo Altayskogo universiteta. 436 p. ISBN 978-5-7904-2258-4. 